\title{
Application of maximum tangential stress criterion in determination of fracture initiation angles of silicon/glass anodic bonds
}

\author{
M.M. Mirsayar ${ }^{a^{*}}$ and A. T. Samaei ${ }^{\mathrm{b}}$
}

${ }^{a}$ Zachry Department of Civil Engineering, Texas A\&M University, College Station, TX 77843-3136, USA ${ }^{b}$ Young Researchers \& Elite Club, Chalous Branch, Islamic Azad University, Chalous, Iran

\begin{tabular}{l}
\hline A R T I C L E I N F O \\
\hline Article history: \\
Received January 25, 2014 \\
Received in Revised form \\
May, 10, 2014 \\
Accepted 7 June 2014 \\
Available online \\
9 June 2014 \\
\hline Keywords: \\
Bi-material notches \\
Maximum tangential stress \\
Fracture initiation angle \\
Silicon/glass anodic bonds
\end{tabular}

A B S T R A C T
Silicon/glass bi-materials are used in micro-assembly and packaging of micro-
electromechanical systems (MEMS) and micro-electronics devices. In this paper, maximum
tangential stress (MTS) concept is used for determination of the fracture initiation angles of
silicon/ glass bi-material notches. First, the MTS criterion is analytically formulated for a bi-
material notch problem. Then, the criterion used for prediction of fracture initiation angles of
some experimental data given in literature for silicon/ glass bi-material notches. In addition, the
modified MTS (MMTS) criterion, which considers the effect of I-stress, was compared with the
MTS criterion and the experimental data. It was shown that MMTS criterion provides more
accurate results than the MTS criterion for estimation of the fracture initiation angle.

(C) 2014 Growing Science Ltd. All rights reserved.

\section{Introduction}

Nowadays bi-material notches can be seen in different modern industrial structures such as aircrafts, automobiles and microelectronics structures. Among them, the use of microelectromechanical systems (MEMS) and micro-electronics devices is going to be increased in order to meet the modern technological needs. These devises contain numerous multi-material and bi-material interface corners (Chen et al., 1997; Dunn et al., 2000; Labossierea et al., 2002; Lu et al., 2002). At the corner of these interfaces, fracture may occur due to the high stress/ strain gradient as a result of material discontinuity and geometrical configuration. In order to understand the effect of each fracture mode (mode I and II) as well as the higher order terms, the analysis of stress field parameters is one of the first steps. Heretofore, elastic stress field of bi-material/ simple notches and cracks has been studied by many researchers (Ayatollahi et al., 2010; Ayatollahi et al., 2011; Mirsayar \& Samaei 2013; Mirsayar 2013; Ayatollahi et al., 2013; Ayatollahi et al., 2010; Arabi et al., 2013; Mirsayar

* Corresponding author. Tel.: +1 (979) 777-6096

E-mail addresses: mirmilad@tamu.edu (M.M. Mirsayar) 
2014). Several fracture criteria are suggested for prediction of fracture initiation angle at the interface corners. These criteria are mostly energy based (like strain energy density and energy release rate) and stress based criteria have not been extended well for bi-material notches (Spyropoulos 2003; Klusak \& Knesl 2007). Recently, Mirsayar et al. (2014) suggested a stress based fracture criterion considering the effect of first non-singular stress term of elastic stress field, called I-stress, to estimate the direction of fracture initiation at the interface corner. They showed that I-stress can play an important role on estimation of fracture initiation angle at the interface and proposed a modified MTS (MMTS) criterion. In this paper, the maximum tangential stress (MTS) criterion is used for prediction of direction of fracture initiation at the corner of the interfaces. First, MTS was formulated for bimaterial notch problems and the direction of fracture initiation was calculated and plotted as a function of mode mixity. Then, the MTS criterion is used for predicting the fracture initiation angles of experimental data presented by Labossiere et. al (2002) for silicon/glass interface corners which are used in MEMS and microelectronics devices (Labossierea et al., 2002; Dunn et al., 2000). Finally, the experimental data and analytical predictions from MTS and MMTS criteria are compared with each other. It is shown that the MMTS provides more accurate estimation of experimental results than the MTS criterion however the difference between the MTS and MMTS predictions is not significant.

\section{MTS criterion}

\subsection{Stress and displacement field at the interface corner}

Let us consider a bimaterial interface corner as shown in Fig. 1.

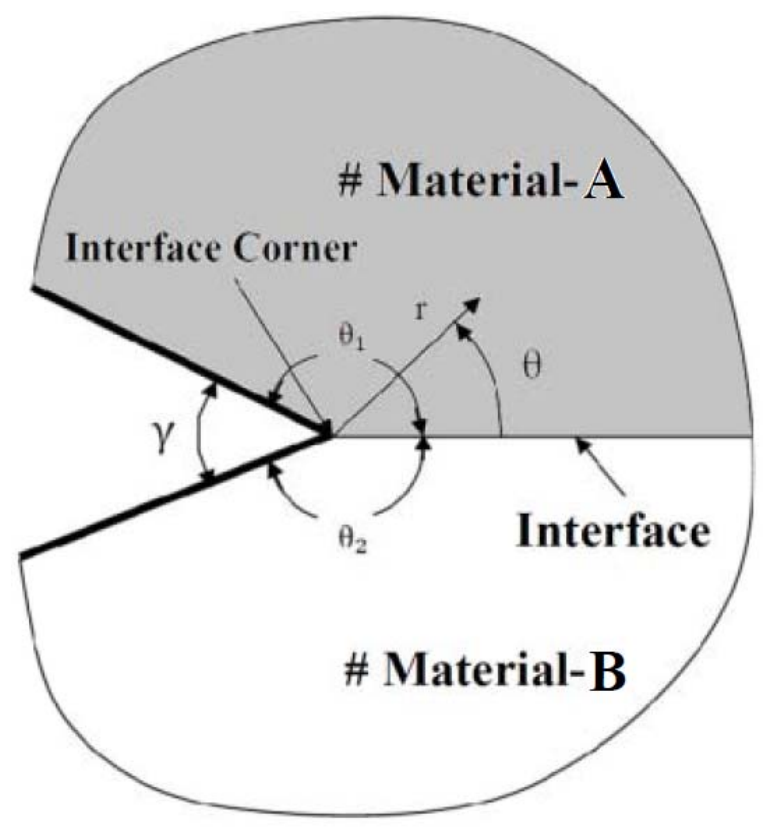

Fig. 1. General configuration of a bi-material notch

The in-plane singular stress and displacement fields near the interface corner can be expressed as (Labossierea et al., 2002):

$\sigma_{i j}^{M}=K_{1} r^{\lambda_{1}-1} f_{i j}^{1 M}(\theta)+K_{2} r^{\lambda_{2}-1} f_{i j}^{2 M}(\theta)+(I-$ stress $)+$ Higher order terms $\left(\lambda_{\mathrm{m}}>1\right)$

$u_{i}^{M}=K_{1} r^{\lambda_{1}-1} g_{i}^{1 M}(\theta)+K_{2} r^{\lambda_{2}-1} g_{i}^{2 M}(\theta)+(I-$ stress $)+$ Higher order terms $\left(\lambda_{\mathrm{m}}>1\right)$

where $(i, j) \equiv(r, \theta)$ are the polar coordinates with the origin at the interface corner, $K_{m}(\mathrm{~m}=1,2)$ are the stress intensity factors, $\lambda_{\mathrm{m}}$ corresponds to the $m$ th eigenvalue of the problem. Also in Eq. (1), $f_{i j}^{m M}$ and $g_{i}^{m M}$ are known functions of $\theta$ and differ in each material $(\mathrm{M}=\mathrm{A}, \mathrm{B})$ (see refs (Ayatollahi 
et al., 2010; Ayatollahi et al., 2011; Mirsayar \& Samaei 2013; Mirsayar 2013; Ayatollahi et al., 2013; Ayatollahi et al., 2010; Arabi et al., 2013; Mirsayar 2014)) for more details).

It is worth mentioning that the full field stress and displacement fields contain infinite terms of singular and non-singular terms. For bi-material notch problems, there are one or two singular stress terms $\left(\lambda_{m}-1<0\right)$ based on the geometrical and material configuration at the interface corner and the higher order ones represent the non-singular terms. Although the non-singular terms, especially the first non-singular one, may sometimes significantly affect the stress distribution adjacent the interface corner (Ayatollahi et al., 2010; Ayatollahi et al., 2011; Ayatollahi \& Mirsayar 2011, Mirsayar et al., 2014; Mirsayar 2014), the singular stress terms mainly cover the stress fields in a wide range of materials, geometrical configurations and loading conditions.

\subsection{MTS criterion for determination of fracture initiation angle}

The MTS criterion for brittle materials states that fracture occurs when the tangential stress component $\sigma_{\theta \theta}^{M}$ reaches to its maximum possible value $\left(\sigma_{\theta \theta, C}^{M}\right)$ at a critical distance of $r_{\mathrm{c}}$ around the notch tip. This criterion has been used earlier for predicting the angle of fracture in cracked brittle or quasi brittle materials (Awaji and Sato 1978; Shetty et al. 1987; Singh and Shetty 1989; Tikare and Choi 1997; Aliha and Ayatollahi 2008, 2009, 2012; Ayatollahi and Aliha 2011, Aliha et al. 2008, 2012; Yamauchi et al. 20011, Marsavina et al. 2013). The fracture initiation angle $\left(\theta_{0}\right)$ could easily be obtained by satisfying the following equation:

$$
\left\{\begin{array}{l}
\left(\frac{\partial \sigma_{\theta \theta}^{M}(\theta)}{\partial \theta}\right)_{\theta_{0}}=0 \\
\left(\frac{\partial^{2} \sigma_{\theta \theta}^{M}(\theta)}{\partial \theta^{2}}\right)_{\theta_{0}}<0
\end{array}\right.
$$

By putting the extended form of tangential stress component from Eq. 1 into Eq. 2, the Eq. 2 can be rewritten as:

$$
\begin{aligned}
& \left(\frac{\partial \sigma_{\theta \theta}^{M}(\theta)}{\partial \theta}\right)_{\theta_{0}}=0 \rightarrow K_{1} r^{\lambda_{1}-1} \frac{\partial f_{\theta \theta}^{1 M}}{\partial \theta}+K_{2} r^{\lambda_{2}-1} \frac{\partial f_{\theta \theta}^{2 M}}{\partial \theta}=0 \rightarrow \theta_{0} \\
& \left(\frac{\partial^{2} \sigma_{\theta \theta}^{M}(\theta)}{\partial \theta^{2}}\right)_{\theta_{0}}<0
\end{aligned}
$$

The Eq. 3 represents the MTS criterion for determining the direction of fracture initiation at the interface corner. It should be mentioned that the Eq. 3considers only singular stress terms and the term corresponding to $\lambda_{2}$ is supposed to be a singular term. Therefore, in cases with only one singular eigenvalue, the term corresponding to $\lambda_{2}$ should not be considered based on the MTS criterion.

The modified version of the MTS criterion (called MMTS criterion), is recently proposed by Mirsayar et al (2014) which considers the effect of I-stress as well as the singular stress field. According to their criterion, the I-stress term can play an important role on estimation of the fracture initiation angle depending on the geometry and combination of materials at the interface. More details about modified version of the MTS criterion can be found in (Mirsayar et al., 2014).

\section{Experimental data and discussion}

In this section, some experimental data for fracture initiation angle of silicon/ glass bi-material notches given by Labossiere et.al (2002) are used for validating the MTS and MMTS criteria. For a silicon/ glass bond with opening angle of $90^{\circ}$, the functions $f_{i j}^{1, M}$ and $f_{i j}^{2, M}$ are given in Figs. 2 and 
3. The first and the second eigenvalues $\left(\lambda_{1}, \lambda_{2}\right)$ associated with this combination of materials and geometrical configuration are 0.505 and 0.822 respectively (Labossierea et al., 2002).

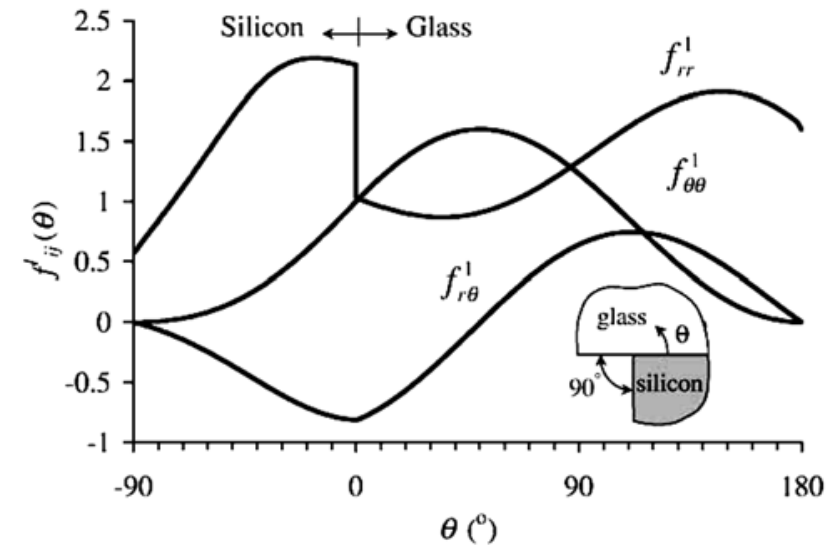

Fig. 2. $f_{r r}^{1}, f_{r \theta}^{1}$ and $f_{\theta \theta}^{1}$ as a function of $\theta$ for the silicon/ glass bi-material interface corner $\theta_{\mathrm{A}}=180^{\circ}$, $\theta_{\mathrm{B}}=90^{\circ}\left(\gamma=90^{\circ}\right)$ (Labossierea et al., 2002)

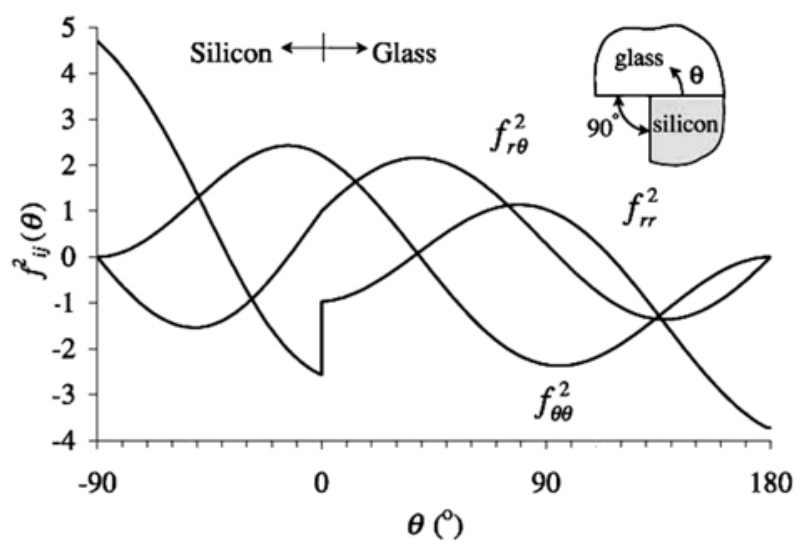

Fig. 3. $f_{r r}^{2}, f_{r \theta}^{2}$ and $f_{\theta \theta}^{2}$ as a function of $\theta$ for the silicon/ glass bi-material interface corner $\theta_{\mathrm{A}}=180^{\circ}$, $\theta_{\mathrm{B}}=90^{\circ}\left(\gamma=90^{\circ}\right)($ Labossierea et al., 2002)

As the fracture always occurred in the glass in all the tested specimens, the critical distance assumed to be 0.05 for glass part. The parameters $\frac{\partial f_{\theta \theta}^{1 M}}{\partial \theta}$ and $\frac{\partial f_{\theta \theta}^{2 M}}{\partial \theta}$ could easily be calculated by numerically derivation of $f_{i j}^{1, M}$ and $f_{i j}^{2, M}$ given in Figs. 2 and 3 as follow:

$\frac{f_{i j}^{m M}(\theta+\Delta \theta)-f_{i j}^{m M}(\theta)}{\Delta \theta},\left(\Delta \theta=0.5^{\circ},-90^{\circ}<\theta<180^{\circ}\right)$.

Table 1 represents the experimental data given in (Labossierea et al., 2002) for the direction of fracture initiation. Based on their results, the fracture was occurred in glass for all of these specimens. The parameter $M^{e}\left(M^{e}=\frac{2}{\pi} \tan ^{-1}\left(\frac{K_{1}}{K_{2}}\right)\right.$, called mode mixity, represents the participation of each fracture mode and varies between zero and one.

Table 1. Experimental data for fracture initiation angles in the silicon/glass bonds with opening angle of $90^{\circ}$ given in (Labossierea et al., 2002)

\begin{tabular}{llll}
\hline$\theta$ (Degrees) & $K_{1 \text { cr }}$ & $K_{2 \text { cr }}$ & $M^{\mathrm{e}}$ \\
\hline 35 & 0.19 & 1.86 & 0.065 \\
38 & 0.19 & 1.94 & 0.062 \\
35 & 0.19 & 2.18 & 0.055 \\
36 & 0.19 & 2.58 & 0.047 \\
\hline
\end{tabular}

The experimental data, given in Table 1 and the analytical predictions by the MTS and MMTS criteria are shown in Fig. 4. It can be seen from Fig. 4 that the MMTS criterion provides more accurate results than the MTS criterion; however the difference between the MTS and MMTS predictions is not significant. The details of MMTS criterion can be found in (Mirsayar et al., 2014). 


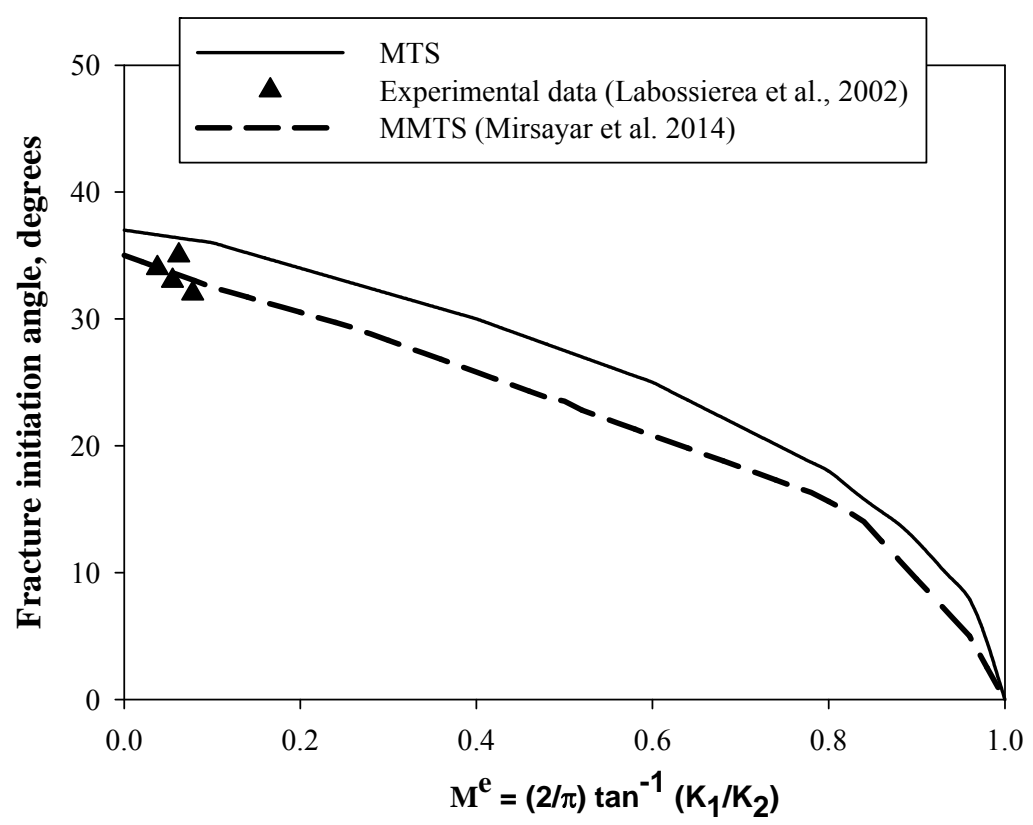

Fig. 4. MTS criterion in comparison with MMTS and experimental data

\section{Conclusions}

The MTS criterion for bi-material notch problems is formulated and applied for some experimental data for silicon/glass interfaces. The direction of fracture initiation was estimated using both MTS and MMTS criterion. For the experimental data discussed in this paper, it was observed that no significant difference exist between the MTS and MMTS predictions. However, it was shown that the MMTS is capable for predicting more accurate results than the MTS criterion in general.

\section{References}

Aliha, M. R. M., \& Ayatollahi, M. R. (2008). On mixed-mode I/II crack growth in dental resin materials. Scripta Materialia, 59(2), 258-261.

Aliha, M. R. M., \& Ayatollahi, M. R. (2009). Brittle fracture evaluation of a fine grain cement mortar in combined tensile-shear deformation. Fatigue \& Fracture of Engineering Materials \& Structures, 32(12), 987-994.

Aliha, M. R. M., Ayatollahi, M. R., \& Pakzad, R. (2008). Brittle fracture analysis using a ring-shape specimen containing two angled cracks. International Journal of Fracture, 153(1), 63-68.

Aliha, M. R. M., \& Ayatollahi, M. R. (2012). Analysis of fracture initiation angle in some cracked ceramics using the generalized maximum tangential stress criterion. International Journal of Solids and Structures, 49(13), 1877-1883.

Aliha, M. R. M., Ayatollahi, M. R., \& Akbardoost, J. (2012). Typical upper bound-lower bound mixed mode fracture resistance envelopes for rock material. Rock Mechanics and Rock Engineering, 45(1), 65-74.

Arabi, H., Mirsayar, M. M., Samaei, A. T., \& Darandeh, M.(2013) Study of Characteristic Equation of the Elastic Stress Field Near Bimaterial Notches. Strength of Materials 45 (5), 598-606.

Awaji, H., \& Sato, S. (1978). Combined mode fracture toughness measurement by the disk test. Journal of Engineering Materials and Technology, 100(2), 175-182.

Ayatollahi, M. R., Dehghany, M., \& Mirsayar, M. M. (2013). A comprehensive photoelastic study for mode I sharp V-notches. European Journal of Mechanics-A/Solids 37, 216-230

Ayatollahi, M. R., Nejati, M., Mirsayar, M. M.(2010). An overdeterministic method for stress analysis of bi-material corners and interface cracks using finite element method, Proceedings of the 9th Conference of Iranian Aerospace Society, Tehran, Iran. 
Ayatollahi, M. R., Mirsayar, M. M., \& Nejati, M. (2010). Evaluation of first non-singular terms in bimaterial notches. Computational Material Science, 50 (2), 752-760.

Ayatollahi, M. R., Mirsayar, M. M., \& Dehghany, M. (2011). Experimental determination of stress field parameters using photoelasticity. Materials \& Design, 32 (10), 4901-4908.

Ayatollahi, M. R. \& Mirsayar, M. M., (2011). Kinking angle for interface cracks. Procedia Engineering 10, 325-329.

Ayatollahi, M. R., \& Aliha, M. R. M. (2011). Fracture analysis of some ceramics under mixed mode loading. Journal of the American Ceramic Society, 94(2), 561-569.

Chen, W.T., Read, D., Questad, D., \& Sammakia, B., (1997). Opportunities and needs for interfacial fracture mechanics in microelectronic packaging industry. Application of Fracture Mechanics in Electronic Packaging, ASME, AMD-Vol. 222/EEP- 20, 183-192.

Dunn, M. L., Cunningham, S. J. \& Labossierea, P.E.W. (2000) Initiation toughness of Silicon/ Glass anodic bonds. Acta materialia. (48), 735-744.

Klusak J., \& Knesl, Z. (2007). Determination of crack initiation direction from a bi-material notch based on the strain energy density concept. Computational Materials Science 39, 214-218.

Labossierea, P.E.W., Dunn,M. L., \& Cunningham,S. J. (2002). Application of bimaterial interface corner failure mechanics to silicon/ glass anodic bonds. Journal of the Mechanics and Physics of Solids, 50, $405-433$.

Lu, T. J., Moore, D. F., \& Chia, M. H. (2002). Mechanics of micromechanical clips for optical fibers, Journal of Micromechanics and Microengineering. (12) 168-176.

Marsavina, L., Constantinescu, D. M., Linul, E., Apostol, D. A., Voiconi, T., \& Sadowski, T. (2013). Refinements on fracture toughness of PUR foams. Engineering Fracture Mechanics.

Mirsayar, M. M., \& Samaei, A. T. (2013). Photoelastic study of bi-material notches: Effect of mismatch parameters. Engineering Solid Mechanics 1 (1), 21-26.

Mirsayar, M. (2013). Calculation of stress intensity factors for an interfacial notch of a bi-material joint using photoelasticity. Engineering Solid Mechanics, 1(4), 149-153.

Mirsayar, M. M. (2014). A new mixed mode fracture test specimen covering positive and negative values of T-stress. Engineering Solid Mechanics 2 (2), 67-72.

Mirsayar, M. M., Aliha, M. R. M., Samaei, A. T. (2014). On fracture initiation angle near bi-material notches - Effects of first non-singular stress term. Engineering Fracture Mechanics 119, 124-131.

Mirsayar, M. M. (2014). On fracture of kinked interface cracks - The role of T-stress. Materials \& Design 61, $117-123$.

Shetty, D. K., Rosenfield, A. R., \& Duckworth, W. H. (1987). Mixed-mode fracture in biaxial stress state: application of the diametral-compression (Brazilian disk) test. Engineering Fracture Mechanics, 26(6), 825-840.

Singh, D., \& Shetty, D. K. (1989). Microstructural effects on fracture toughness of polycrystalline ceramics in combined mode I and mode II loading. Journal of Engineering for Gas Turbines and Power, 111(1), 174-180.

Spyropoulos, C.P. (2003). Crack initiation direction from interface of bonded dissimilar media. Theoretical and Applied Fracture Mechanics. 39, 99-105.

Tikare, V., \& Choi, S. R. (1997). Combined Mode I-Mode II Fracture of 12-mol\%-Ceria-Doped Tetragonal Zirconia Polycrystalline Ceramic. Journal of the American Ceramic Society, 80(6), 1624-1626.

Yamauchi, Y., Nakano, M., Kishida, K., \& Okabe, T. (2001). Measurement of mixed-mode fracture toughness for brittle materials using edge-notched half-disk specimen. Journal of Society of Materials Science of Japan, 50, 229-234. 